\title{
Employee responses to pay transparency
}

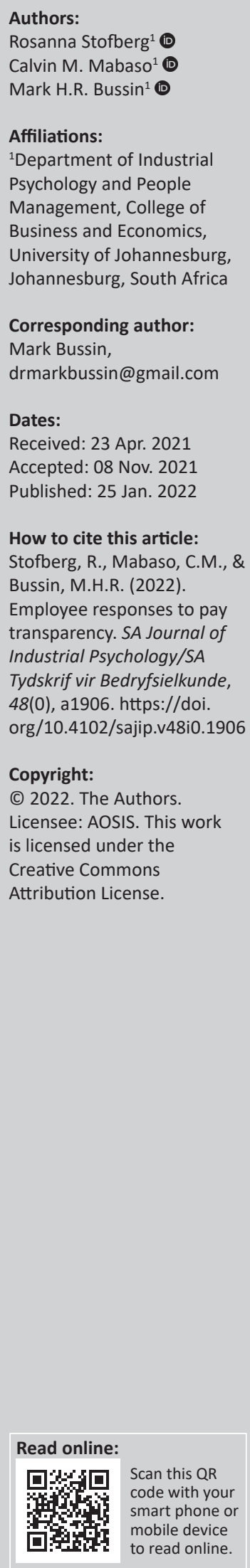

Orientation: Pay transparency is a controversial but understudied topic. The emerging research is developing theory and exploring the impact on organisational outcomes; however, our understanding of employees' perceptions of and responses to pay transparency is limited.

Research purpose: This research study aimed to explore what employees understand of the term 'pay transparency' and how they respond to it.

Motivation for the study: This study contributes to a better understanding of how employees in South African organisations perceive pay transparency.

Research approach/design and method: Semi-structured qualitative interviews were conducted with 20 employees of four organisations with different pay transparency practices. Thematic analysis was used to analyse the data.

Main findings: Employees in this study have diverse understandings and views of pay transparency and relatively low expectations of employers. However, they can thoughtfully conceptualise the potential risks and benefits of greater pay transparency. The metaphor of the sport fan is useful to explain this phenomenon - standing at the side-lines with strong opinions but removed from the action.

Practical/managerial implications: Understanding how employees perceive pay transparency can help employers and practitioners to navigate their pay transparency approach.

Contribution/value-add: As the only known qualitative study in the pay transparency field, this study gives unique insights into employees' perceptions of and responses to pay transparency.

Keywords: pay transparency; pay inequality; qualitative research; thematic analysis; compensation; reward; South Africa.

\section{Introduction}

Pay transparency is often seen as a controversial topic (Birkinshaw \& Cable, 2017). Companies that have disclosed information about what employees earn frequently make headlines (Loudenback, 2017), and some argue that the prevalence of online salary sharing tools such as Glassdoor.com will make pay transparency something that younger generations will simply expect of their employers (Marasi \& Bennett, 2016). This trend has naturally made some employers and human resource (HR) practitioners nervous that greater transparency could expose pay inequalities, cause reputational damage or increase costs (Zenger, 2016). These potential impacts remain understudied in the academic literature, as do the potential impacts of pay transparency on various organisational outcomes such as job turnover and employee satisfaction (Smit \& Montag-Smit, 2018; Trotter, Zacur, \& Stickney, 2017), making it harder for employers and HR to know how to handle pay transparency.

Pay transparency is defined as the degree to which employers disclose information about how they determine pay (process transparency), how much they pay (outcome transparency) and how much they permit employees to discuss pay (communication transparency) (Arnold, Fulmer, Sender, Allen, \& Staffelbach, 2018; Colella, Paetzold, Zardkoohi, \&Wesson, 2007). Pay transparency is widely agreed to be a continuum from highly secretive to very open. It is best thought of as a collection of practices (process, outcome and communication practices) that together create an organisation's approach to pay transparency (SimanTov-Nachlieli \& Bamberger, 2020).

As the field of pay transparency develops and popular and academic interest in it continues, several strands of literature have emerged. Firstly, theoretical and philosophical reviews explore the possible benefits and costs of pay transparency and consider the current state of knowledge in this area (see Colella et al., 2007; Marasi \& Bennett, 2016; Moriarty, 2018; Trotter et al., 2017). Secondly, there are analyses of pay transparency and its possible role in reducing pay inequality, 
especially the gender pay gap (see Castilla, 2015; Kim, 2015). Pay inequality remains a perennial challenge (Rubery \& Grimshaw, 2015) so this is, of course, an important line of enquiry. Then, looking at empirical investigations, there are various studies that have tested different types of pay transparency conditions in laboratory settings (e.g. Bamberger \& Belogolovsky, 2010; Belogolovsky \& Bamberger, 2014) and studies that have taken public data on the performance of sports teams and their pay to analyse the link between the two (e.g. Hill, Aime, \& Ridge, 2017; Sieweke, Köllner, \& Süß, 2017). Finally, more recent studies have aimed to either extend the theoretical understanding of the concept and how to measure it (Marasi, Wall, \& Bennett, 2018; Smit \& MontagSmit, 2019) or investigate the impact of pay transparency on various organisational outcomes, such as job turnover, performance or workplace behaviours (Alterman et al., 2020; Arnold et al., 2018; SimanTov-Nachlieli \& Bamberger, 2020).

However, what is missing in the research, to date, is an understanding of how employees perceive and respond to different pay transparency practices. Previous research studies have shown that satisfaction with pay impacts job satisfaction, and that pay satisfaction is related to how pay is perceived relative to peers' income (De Coning, Rothmann, \& Stander, 2019). Pay transparency practices can be an important contributor to these perceptions.

Pay transparency laboratory experiments, which are removed from a workplace context, and analysis of sports data obviously cannot provide this insight. Even studies that have engaged with people in their role as employees tend to focus on the employer's pay transparency policy (e.g. Marasi et al., 2018; Smit \& Montag-Smit, 2018). Smit and Montag-Smit's (2019) later work exploring employee preferences with regard to pay transparency and Scott et al.'s (2015; Scott, Antoni, Grodzicki, Morales, \& Peláez, 2020) studies of global pay transparency preferences are the only research studies, to date, that take an employee-centred stance, and even then, employees' views are assessed through quantitative surveying. Without the employees' perspective, a full understanding of pay transparency and its impact within organisations will be incomplete. This study, therefore, aims to address this gap in the research.

\section{Research purpose and objectives}

This study aimed to explore how employees perceive pay transparency and how their experiences with their employers shape their response to different pay transparency practices. A qualitative approach was taken to allow themes and ideas to emerge through the research process, as opposed to narrowing the scope of the enquiry upfront. These findings add an employee perspective to the emerging understanding of pay transparency and its impact on the workplace.

\section{Literature review}

Despite the perception of pay transparency as controversial, scholars have theorised that there are several potential benefits of increased pay transparency that should be considered and weighed against the potential risks. Assessing the benefits and risks of pay transparency can be undertaken from an employer or employee perspective. Some of the suggested benefits of transparency for employees would be viewed as costs by employers (Ramachandran, 2012). As determining a pay transparency approach is the employer's responsibility, the benefits and risks will be argued from their perspective.

\section{The benefits of pay transparency}

This section outlines the potential benefits of pay transparency, being reducing inequality, improving motivation and performance, creating an enhanced sense of organisational justice and improving labour market efficiency.

Reducing inequality: Possibly the most compelling benefit of pay transparency is the argument that transparency could reduce inequality in pay (Marasi \& Bennett, 2016; Trotter et al., 2017). Transparent pay systems allow employees to monitor, identify and address disparities in pay (Kim, 2015), and may deter employers from making discriminatory or unjustified pay decisions (Moriarty, 2018; Ramachandran, 2012).

No studies of pay transparency and inequality in South Africa could be found. Bosch and Barit (2020) investigated pay transparency regulation as a potential mechanism to reduce inequality in South Africa but do not provide empirical findings on the effects. Ramachandran's (2012) U.S. study ascribes the smaller gender wage gap for U.S. federal government workers, compared with other workers, at least in part to the transparency of federal government salaries. He also highlighted some studies that found smaller wage gaps in unionised (and generally more transparent) compared with non-unionised organisations. When pay secrecy was prohibited, Kim (2015) found that the gender wage gap was reduced, especially for college-educated women. Similarly, Castilla (2015) showed a reduction in the wage gap for women and ethnic minorities in his longitudinal study of an organisation before and after it introduced greater (but not full) transparency in performance and reward decisions.

Obloj and Zenger (2020) studied the pay data of almost 100000 U.S. academics over a time period of increasing public access to this type of information. They found a trend of reducing pay inequity and a narrowing of the gender pay gap, although this came at the cost of a reduced link between pay and performance. Cullen and Pakzad-Hurson's (2017) analysis of TaskRabbit data (an online marketplace for shortterm tasks and services) found that being able to negotiate in a fully transparent environment (the nature of the TaskRabbit platform clearly shows how much is being paid for each task) equalises pay between men and women. However, they also found that men benefit disproportionately in partially transparent environments, because they are more likely to openly discuss pay amongst themselves. This small sample of studies is not sufficient to argue that reduced pay inequality 
is always a natural consequence of transparency, but it does lend support to the idea of a positive relationship between pay transparency and pay equality.

Motivation and performance:Proponents of pay transparency argue that it could increase employee motivation by amplifying the link between pay and performance (Colella et al., 2007; Ramachandran, 2012) and showing employees the potential rewards if they work hard enough to be promoted (Lawler, 1966). Lawler's $(1965,1966)$ seminal work in this field proposes that transparency, or some degree of it, enhances employees' perception of being treated fairly by their organisation, reduces dissatisfaction with pay and increases motivation to perform.

Cullen and Perez-Truglia (2018) demonstrated the motivational effect of pay transparency in their study. These authors found that employees who were told the salaries of managers just a few promotional steps above them, worked longer hours and made higher sales. It is important to note that some authors have argued that the beneficial link between pay transparency and performance is closely tied to environments where performance can be objectively measured and where differentials in performance are visible to the relevant employees (Bamberger \& Belogolovsky, 2010; Futrell \& Jenkins, 1978).

Organisational justice: Pay transparency has also been linked to perceptions of organisational justice. Organisational justice is an overarching concept that includes distributive justice (fair outcomes) and procedural justice (fair process) (Colquitt, 2001). Clear and transparent communication of pay practice enhances employees' perceptions of fairness and organisational justice (Day, 2011). In addition, confidence in pay decisions being made fairly has a positive influence on satisfaction with pay (Scheller \& Harrison, 2018; Williams, Brower, Ford, Williams, \& Carraher, 2008). Higher perceptions of organisational justice have been associated with higher levels of organisational commitment and trust (Colquitt, Conlon, Wesson, Porter, \& Ng, 2001). The perception of organisational justice related to pay is important in this regard (Marasi \& Bennett, 2016).

Labour market efficiency: One of the final benefits from an economic standpoint is that pay transparency can improve the efficiency of the labour market (Cullen \& PakzadHurson, 2017). Employers can recruit more efficiently because they are able to eliminate negotiations over pay. However, by reducing information asymmetries between employees and employers, employees potentially become more mobile as they attempt to optimise the reward they receive for their particular skills (Colella et al., 2007; Estlund, 2012; Moriarty, 2018).

\section{The risks of pay transparency}

When employees are provided with more information about organisational pay practices it not only reduces the information asymmetry affecting labour market efficiency but can also shift the information balance between employees and employers in ways that could be costly for employers (Ramachandran, 2012), as discussed below.

Employee morale, discontent and conflict: The risk of pay transparency for employers is that upon learning about pay inequalities, employees may become less motivated (Hill et al., 2017), less willing to put in effort and perform (Bellé, 2015; Cullen \& Perez-Truglia, 2018; Frey, Schaffner, Schmidt, \& Torgler, 2013; Nosenzo, 2013) and less satisfied with their pay (Card, Mas, Moretti, \& Saez, 2012; Lawler, 1966). There could also be more workplace conflict, jealousy, anger and other negative emotional consequences (Bamberger \& Belogolovsky, 2017; Colella et al., 2007; Moriarty, 2018; Rosenfeld, 2017). Birkinshaw and Cable (2017) argued that the downside of pay transparency is that sharing information can backfire, causing employees to view the relationship between employer and employee as more transactional. It could further erode trust and motivation. Aside from the fact that employers would generally want at least neutral and hopefully positive relationships with employees, lowered employee morale and an increase in workplace conflict could impact productivity and cost in terms of managing time spent in resolving issues or defending the employer's practices (Estlund, 2012; Rosenfeld, 2017).

Performance: In the field of professional sports, Frey et al. (2013) found that players who view their relative income positioning as low and trending lower will reduce their effort to perform. Nosenzo (2013) found that effort decreased under conditions of pay transparency. Bellé (2015) found that performance incentives were less effective amongst nurses when the outcomes of the incentives were disclosed. These findings appear to contradict the earlier argument that pay transparency improves performance. Zenger (2016) argued that pay transparency negatively impacts performance because employees find it difficult to realistically assess their own performance. He found that more than $30 \%$ of employees rated their own performance in the top 5\% and more than $99 \%$ rated themselves in the top $50 \%$. This means that when confronted with information about non-uniform pay, employees may struggle to reconcile their perceptions of fair pay with their perceptions of their own performance (Moriarty, 2018).

Pay transparency may also reduce differentiation according to performance because managers may compress performance ratings to avoid explaining performance differences to employees (Belogolovsky \& Bamberger, 2014). Leventhal, Michaels and Sanford (1972) demonstrated that managers compressed pay allocations between high and low performers in an attempt to avoid potential conflict with employees.

Pay compression and cost: Research by, for example, Kim (2015), Ramachandran (2021), Trotter et al. (2017) and Zenger 
(2016) found that employers may fear that pay transparency will create pay compression, thereby inflating costs and reducing their ability to reward performance. Indeed, Almeida (2016) found that changes to chief executive officer (CEO) pay disclosure rules in France had the effect of increasing pay for lower-paid CEOs as they caught up to higher performing peers.

In contrast, Mas (2014) found that pay transparency for city managers in the United States led to pay compression, but, in this case, reduced the pay for top-earning city managers because of public pressure. Cullen and PakzadHurson's (2017) study of TaskRabbit data also found pay compression in favour of the organisation under transparent pay conditions - a $10 \%$ reduction in the total salary bill - which they attributed to employers being able to more efficiently make final, non-negotiable offers. More recently, Obloj and Zenger (2020) found evidence of pay compression (lower increases for overpaid employees and higher increases for underpaid employees), although they do not report evidence on the overall cost impact on the organisations.

Employee privacy: A further risk of pay transparency is that sharing pay-related information may erode employee's trust. Employees may feel that the organisation no longer protects their privacy and treats their personal information with care (Burroughs, 1982; Colella et al., 2007; Estlund, 2012; Marasi \& Bennett, 2016). In this regard, ethics scholars have argued that organisations have a duty to respect employees' privacy and handle their information in a sensitive manner (Moriarty, 2018).

Competitive advantage: Finally, by disclosing more pay information, employers may lose some of their competitive advantage, in so far as they see their compensation strategies as a competitive differentiator (Estlund, 2012). It could also result in an organisation's workforce being more mobile because they are aware of more lucrative opportunities elsewhere (Colella et al., 2007).

\section{Employee responses to pay transparency}

At this point, it is essential to note that, whilst benefits and risks may be relevant at an organisational level, individual employees may not respond to pay transparency in a uniform way (Colella et al., 2007; Fulmer \& Shaw, 2018). Studies of pay preferences by Scott et al. $(2015,2020)$ showed that employee responses differed according to nationality, age and current pay level (with lower-paid people preferring more transparency). Bamberger and Belogolovsky (2010, 2017) found that the impact of pay transparency differed between those with a high and a low tolerance for inequity (i.e. a sensitivity towards equity in social exchanges) and for those with higher versus lower beliefs of the importance of individualism. Smit and Montag-Smit (2018) showed that employees have different pay transparency preferences, and that these preferences influence job attitudes. Employees' relative pay positioning also impacts their perceptions of pay equity, with lower-paid employees responding differently to transparency than higher paid employees (SimanTovNachlieli \& Bamberger, 2020; Trevor \& Wazeter, 2006).

Clearly, individual employee characteristics and contextual factors play a role in how employees respond to different pay transparency practices. Fulmer and Shaw (2018) have proposed compensation activation theory to explain this mechanism. The idea is that because of individual differences, different employees will respond to aspects of an organisation's pay practices with different intensity depending on whether that pay practice triggers something particularly relevant for that person.

Considering the theory about the benefits and risks of pay transparency, the question remains as to how this aligns with how employees respond to pay transparency and if they respond to it in unique individual ways.

\section{Research design}

This section explains how the study was designed, including the research philosophy and approach, the research methods employed, the sample, the data collection and analysis techniques and how data quality and ethical considerations were managed.

\section{Research approach and strategy}

The data and findings reported here were part of a larger research project that used an explanatory sequential mixedmethods research design to explore the impact of pay transparency on job turnover intentions. The understudied nature of pay transparency makes it well suited to a mixedmethods approach (Creswell \& Plano Clark, 2018). A pragmatic research philosophy was adopted in this study. Pragmatism's focus on research methods that address the research question with a practical, real-world orientation (Creswell \& Plano Clark, 2018) made it an appropriate fit for a mixed-methods approach and aligned well with the research questions, which guided the overall study. The overall study consisted of a quantitative survey followed by qualitative interviews that explored the findings from the survey. This article reports only on the qualitative component of the study, and in particular, the data and findings related to employee responses to pay transparency.

The qualitative research design has many things in common with the grounded theory approach described by Creswell (2013), as it consisted of interviews, following by coding of the resulting interview data. However, as a part of a larger mixed-methods study, this was not a true grounded theory study. A qualitative research design was chosen as most suitable to elicit detailed, rich descriptions of how employees perceive pay transparency and provide more nuance than is possible through quantitative methods (Bryman, 2008). 


\section{Research method}

\section{Research setting}

A convenience sample of organisations with diverse pay transparency practices were contacted to participate in the study. Four organisations spanning the pay transparency continuum (Burroughs, 1982), from very secretive to the relatively transparent pay practices of the South African government agreed to participate in the research. The organisations in the study were quite diverse - a small family-owned financial services company, a ministerial department of the South African government, a large fastmoving consumer goods (FMCG) company and a large communications and technology company.

Employees from each organisation were surveyed, with a total of 299 responses. Respondents were asked if they would be willing to participate in a follow-up interview and the sample for the qualitative interviews was selected from this group of volunteers.

\section{Entrée and establishing researcher roles}

Senior 'gate-keepers' at each organisation, usually the HR director or manager, were approached to request permission to conduct the research. Once permission was granted and the survey was completed, only survey respondents who had volunteered to be interviewed were contacted. The first author conducted all interviews face-to-face (pre-COVID 19), at a time and place of the participants' choice. The researcher clarified that participants' data would be treated confidentially and nothing they said would be reported back to their employer.

\section{Research participants and sampling methods}

A purposive quota sampling approach (Daniel, 2012) was used to select 20 interview participants that most closely matched the demographic profile of the survey respondents from the group of volunteers. Appropriate sample size in qualitative research cannot be prescribed; however, the sample here falls within the guidelines provided by Creswell and Adler and Adler of between 12 and 30 interviews (Baker \& Edwards, 2012; Creswell, 2013). The aim of the qualitative interviews was to understand the survey results in more detail, which is why a similar profile of participants was selected. The interview sample was $55 \%$ male $(n=11)$, with a median age of 39 and a median tenure of 10 years in that specific organisation. The majority of the sample was in either middle $(40 \%, n=8)$ or junior $(30 \%, n=6)$ management roles. A minimum of three and a maximum of seven interviews were carried out per organisation. The profile of the interview participants is provided in Table 1.

\section{Data collection methods}

A semi-structured interview technique is a commonly used qualitative data collection technique. It is well suited to studies where specific lines of enquiry need to be explored, whilst still making space for the interviewee to add nuance, commentary and additional themes for consideration (Bryman, 2008). Before conducting the interviews, an interview guide was developed, enabling the researcher to guide the semi-structured interviews.

The pay transparency interview questions aimed first to get a sense of how participants understood the concept, with further questions then probing views around the potential risks and benefits of greater pay transparency and the participants' views on what they would like to see their employer do differently. One of the purposes of conducting the interviews was to elicit richer information about people's experiences around pay, so questions about how

TABLE 1: Interview participants' demographic profile.

\begin{tabular}{|c|c|c|c|c|c|c|}
\hline Identifier & Organisation & Age & Gender & Tenure (years) & Job level & Work type \\
\hline P1 & Organisation 4 & 45 & Male & 20 & Senior management & Operations \\
\hline P2 & Organisation 4 & 39 & Female & 16 & Junior management/skilled & Tech/IT \\
\hline P3 & Organisation 2 & 38 & Female & 1 & Junior management/skilled & Finance \\
\hline P4 & Organisation 1 & 56 & Female & 20 & Semi-skilled & Sales \\
\hline P5 & Organisation 2 & 37 & Male & 13 & Senior management & Tech/IT \\
\hline P6 & Organisation 4 & 44 & Male & 23 & Middle management /professional & Sales \\
\hline P7 & Organisation 1 & 32 & Male & 3 & Middle management /professional & Operations \\
\hline P8 & Organisation 1 & 58 & Female & 1 & Middle management /professional & Compliance/legal \\
\hline P9 & Organisation 3 & 34 & Female & 5 & Middle management /professional & Research and policy \\
\hline P10 & Organisation 2 & 30 & Female & 9 & Semi-skilled & Operations \\
\hline P11 & Organisation 2 & 59 & Male & 18 & Junior management/skilled & Operations \\
\hline P12 & Organisation 4 & 36 & Male & 3 & Junior management/skilled & Tech/IT \\
\hline P13 & Organisation 2 & 26 & Male & 7 & Junior management/skilled & Tech/IT \\
\hline P14 & Organisation 1 & 38 & Male & 1 & Middle management /professional & Tech/IT \\
\hline P16 & Organisation 3 & 35 & Male & 13 & Middle management /professional & Research and policy \\
\hline P17 & Organisation 4 & 41 & Female & 12 & Middle management /professional & Compliance/legal \\
\hline P18 & Organisation 4 & 52 & Female & 19 & Middle management /professional & Operations \\
\hline P19 & Organisation 2 & 39 & Male & 7 & Semi-skilled & Operations \\
\hline P20 & Organisation 3 & 49 & Male & 11 & Senior management & Research and policy \\
\hline
\end{tabular}

IT, information technology. 
participants perceived their own level of pay relative to others and what informed that view were included. Participants were also asked how they generally felt about their employer and whether they had considered leaving the organisation and why.

\section{Data recording}

A total of 20 interviews were conducted, each lasting $30 \mathrm{~min}-$ $60 \mathrm{~min}$, over a month in October and November 2019. With participants' consent, interviews were audio-recorded. The recordings were securely stored electronically and then transcribed verbatim. Transcripts were proofread alongside the recording to ensure accuracy. The researcher also took notes during the interviews and recorded thoughts and insights immediately following each interview. These notes were also typed up to be included in the analysis.

\section{Data analysis}

All data collected were imported into ATLAS.ti Version 8 for analysis. The thematic analysis procedures outlined by Braun and Clarke (2006) were followed, starting with immersion in the data and then assigning codes, or short descriptions, to items of interest in the text. Olivier (2017) followed the same process. A combined deductive and inductive approach was taken to develop the codes, harnessing the flexibility of the thematic analysis method (Braun \& Clarke, 2006). Codes were reviewed, refined and grouped into categories. Through progressive iterations, themes (higher level, more abstract ideas) were identified in the data.

\section{Strategies employed to ensure data quality and integrity}

Braun and Clarke (2006) offered a 15-point checklist to conduct high-quality thematic analysis. This covers the full process of data preparation and analysis, starting with ensuring the accuracy and completeness of the interview transcripts. Rigorous thematic analysis is dependent on completeness and coherence of the set of codes, comprehensive analysis and interpretation of the themes developed from the codes and a methodologically consistent approach to writing up the results. A concerted effort was made to conduct the thematic analysis rigorously and report it accurately.

King and Brooks (2018) proposed three strategies to enhance quality in thematic analysis. The first is inter-coder comparison, where the data are coded by multiple people, who then compare their coding. In this case, the coding was conducted by the first author and was reviewed by the coauthors. The second strategy is participant feedback, where the findings of the analysis are shared with participants for feedback. In this study, participant feedback on the emergent themes was not sought, as each participant described his or her personal work experiences and would therefore not have been in a position to assess themes that emerged from other participants' data. Finally, audit trails, or notes and records of how the thematic analysis progressed and where codes and themes were added, removed or changed during the process, could demonstrate rigour in the analysis. Such an audit trail was maintained for this study.

\section{Reporting style}

The findings are reported under each of the themes that were identified. Participants' quotes are included to support the identified themes and show how the participants expressed themselves.

\section{Ethical considerations}

The main ethical considerations for this study were protecting the anonymity of participants in terms of storing data securely and privately and writing up the findings in a way that did not disclose identifying details (Creswell, 2013). Participants were given clear information about the study and advised of their right to withdraw without consequences at any time. The study was approved by the research ethics committee of the researcher's university prior to data collection (Ethics clearance: IPPM2018-235).

\section{Results}

Because the limited pay transparency literature tends to focus on the benefits and costs of pay transparency, these ideas were sought in the interview data (a deductive approach) and are described under the theme 'people can conceptualise the benefits and risks of more pay transparency.' The rest of the codes and categories were inductively analysed, with themes emerging from the data, an approach aligned with the understudied nature of pay transparency. The three additional themes that emerged were as follows:

- High levels of pay transparency are not expected of the employer.

- Views on pay transparency are diverse.

- Pay inequality concerns are not directly tied to pay transparency.

Table 2 summarises the categories and subcategories for each theme and these are explained in more detail in the sections that follow.

\section{High levels of pay transparency are not expected of the employer}

During the interviews, it became apparent that the participants' understanding of pay transparency varied from completely misunderstanding the concept and thinking it was related to whether they received their payslip timeously, to a more sophisticated understanding that aligned with the definition of concept being researched. This finding shows that employees do not have a consistent understanding of what pay transparency means.

When asked about how they felt about the information their organisation provided about pay, eight participants related the question to information they received about their own pay, benefits and increases, instead of considering organisational pay practices:

'... Pay related, I would say satisfied. Communication is quite open when it comes to things regarding your benefits statement or a query on medical aid on your salary slip. That type of thing. 
TABLE 2: Pay transparency themes, categories and subcategories.

\begin{tabular}{|c|c|c|}
\hline Theme & Category & Sub-category \\
\hline \multirow[t]{9}{*}{$\begin{array}{l}\text { High levels of pay transparency are not expected of the } \\
\text { employer }\end{array}$} & \multirow[t]{3}{*}{ Understanding of pay transparency } & $\begin{array}{l}\text { Satisfied with pay transparency: Understands it to be information } \\
\text { about own pay and benefits }\end{array}$ \\
\hline & & Limited understanding of pay transparency \\
\hline & & $\begin{array}{l}\text { Satisfied with pay transparency: Understands it to be about } \\
\text { increases }\end{array}$ \\
\hline & \multirow[t]{2}{*}{ Satisfied with pay transparency } & Satisfied with pay transparency: Expected and normal \\
\hline & & $\begin{array}{l}\text { Satisfied with pay transparency: Information provided meets } \\
\text { expectations }\end{array}$ \\
\hline & \multirow[t]{4}{*}{ Not satisfied with pay transparency } & Pay communication: Not satisfactory/insufficient \\
\hline & & Not satisfied with pay transparency: General \\
\hline & & Not satisfied with pay transparency: Concerns regarding equal pay \\
\hline & & No transparency in benchmarking \\
\hline \multirow[t]{4}{*}{ Views on pay transparency are diverse } & \multirow[t]{4}{*}{ Position on pay transparency } & Pay transparency is a complex topic \\
\hline & & Comfortable with full pay transparency \\
\hline & & Against full pay transparency \\
\hline & & $\begin{array}{l}\text { Some pay transparency acceptable, if pay differentiation is } \\
\text { explained }\end{array}$ \\
\hline \multirow{5}{*}{$\begin{array}{l}\text { Pay inequality concerns are not directly tied to } \\
\text { pay transparency }\end{array}$} & \multirow[t]{4}{*}{ Concerns about pay inequality } & Concerned about pay inequality in organisation \\
\hline & & Concerned about pay inequality generally \\
\hline & & Concerned about low salaries of junior people \\
\hline & & Becoming more concerned and vocal about equal pay \\
\hline & Response to different/unequal pay & Pay differences acceptable if justified \\
\hline \multirow{13}{*}{$\begin{array}{l}\text { People can conceptualise the benefits and risks of more } \\
\text { pay transparency }\end{array}$} & \multirow[t]{6}{*}{ Benefits } & Motivational \\
\hline & & More information to make better decisions \\
\hline & & Force more equal or fair behaviour \\
\hline & & Create more trust in organisation \\
\hline & & Create sense of agency and worth \\
\hline & & Transparency inherently good \\
\hline & \multirow[t]{7}{*}{ Risks } & Demotivation/disengagement/attrition \\
\hline & & Information not understood, employees unhappy \\
\hline & & Inflate costs \\
\hline & & $\begin{array}{l}\text { Change information asymmetry between organisation and } \\
\text { employees }\end{array}$ \\
\hline & & Reputational risk if there is inequality \\
\hline & & Lose competitive advantage \\
\hline & & No risks \\
\hline
\end{tabular}

Yes, I would say quite easy to access and easy to get feedback, yes.' (P15, female, 38, junior management)

'So your increase letter is your increase letter. And that is published. You can go and download it and get it and it goes onto your file and all of that. But that's pretty consistent. So, I don't think there is anything else that they can do, you know.' (P18, female, 52, middle management)

'So everything is transparent, so, when you are joining you know upfront ... all of that is broken down, your medical, your other things and the 13th cheque, which is also included...So it's all defined upfront. So, when you commit or sign that contract, you know what you are up for.' (P20, male, 49, senior management)

Eight participants expressed satisfaction with the level of pay transparency in their organisations. These sentiments were grouped as either satisfaction because information provided met their expectations or satisfaction because they perceived current levels of pay transparency as standard. The idea of information meeting expectations aligned with how participants understood pay transparency. Participants expressed satisfaction with the information they received when they believed it to be about their own pay and benefits:
'[Organisation 2] is one of the best companies to work for with the benefits, you will know everything about your pension, Unemployment Insurance Fund (UIF). That's what I like about it, they don't keep us in the dark.' (P10, female, 30, semi-skilled)

'I am satisfied. When I check the payment from [Organisation 2], I know not many other companies will give what I get from [Organisation 2]. Pension, UIF, bonus and increment. Not many other companies give that. And I get notified when the bonus is going to be paid.' (P19, male, 39, semi-skilled)

'The salary structure... So all these things are quite very transparent. And it's up to you. If you don't want, they will indicate that, ok, if you want us to implement as is, that's fine, we'll go ahead with it. And they will do it. So, if that's what you want.' (P20, male, 49, senior management)

Participants generally did not seem to expect something more or different from their employers. Five expressed comfort or satisfaction with the level of pay information they received. They perceived their organisation's practices as normal. As Participant 14 (male, 38, middle management) said, 'I'm ok with it. It's because that's how companies do it in this country.' It is interesting to note that this general sentiment cut across the different organisations. Although the four organisations 
have different levels of pay transparency, participants seemed to generally view the situation they experienced as normal and what they expected. Even where they had experienced more transparency at previous employers they viewed that as 'nice to have' and a possible improvement, but not a serious deficiency in their current employer:

'Probably some sort of bracketing such as the previous company where they said, you're on this level and this is how you get to the next level. Because there isn't any of that in this company ... having levels saying this is where you are and this is where you can get to would be nice.' (P14, male, 38 , middle management)

Not all participants were entirely satisfied with the level of pay transparency in their organisation. The biggest source of dissatisfaction was insufficient or unsatisfactory communication about pay, usually in relation to annual or promotional increases. Frustrations were expressed about opaque processes around increases, unprofessional handling of increases, having to motivate for one's own increase when promoted, unmet expectations around increases for changes in work responsibilities, unions communicating more effectively than the employer did and a lack of 'voice' or ability to influence the increment process.

'They'd like us to believe that there's an open door policy around things like that, but I mean, when you have to write a motivation for an increase and you've been promoted that speaks volumes already.' (P2, female, 39, junior management)

'Our process, they say it's clear but it's really not. You get what you get.' (P17, female, 41, middle management)

'He'd offered me the position telephonically. We met for coffee, I said, "I'm in." And then, he said to me, "Just sign this," and then I saw, oh, ok, there's an increase. Cool. So, not dissatisfied, I just think it would, that's not professional, I don't think.' (P5, male, 37 , senior management)

Overall, the key finding in this theme is that participants do not appear to expect, nor highly value, the types of pay transparency practices that exist on the more 'open' end of the pay transparency spectrum. This may be partially because some participants (especially more junior employees) have a limited understanding of the concept of pay transparency and perhaps do not know that a more open approach to pay is even an option. However, even if the participants did not expect a more open approach, they did express frustration with how communication around pay, particularly increments, was handled, and felt strongly that there was room for improvement in this area:

'Uh, not that satisfied. I think it [communication] doesn't come as frequent as we would like, and when it does, it sort of comes randomly. So, there isn't a time where we know that around July, that's when we get to know what's happening... Um, so, I think, not that satisfied because it doesn't come frequently or it doesn't come, it isn't as predictable.' (P9, female, 34, middle management)

'I feel like everybody is coached into saying the same thing... So, that is my problem. I don't feel like there is honest communication about what it takes to get to a certain point.' (P2, female, 39, junior management)

\section{Views on pay transparency are diverse}

Smit and Montag-Smit (2018) found that individual preferences shaped the way that employees respond to different pay practices, meaning that people within the same organisation may not react uniformly towards a particular organisational practice. The data in this study confirmed that participants held a wide range of diverse views about pay transparency and related matters.

Stances on pay transparency spanned the full transparency continuum, although the extreme positions on full transparency (for or against) were only expressed by one participant each. Instead, more participants took a more moderate stance of acknowledging the complexity of the topic and seeing a need for balance in what information is shared:

'If you're asking me if I should share my salary with my peer, then I think it's a dangerous thing. So I would say I'm against that level of pay transparency.' (P6, male, 44, middle management)

'If you put up a board with everyone's salaries, I'd be perfectly fine with that.' (P7, male, 32, middle management)

'It's [pay transparency] a double-edged sword. I think every time I've sat and I've thought about this from an employment equity committee, from a gender perspective. It is such a double edged sword because I have to look at it from a business perspective too. If this was my business, what would I do? I don't think I would ever go full transparency. But, I do believe I would make a lot more effort, in the way I find a way to communicate to my employees.' (P17, female, 41, middle management)

These data show the diversity of views about pay transparency and how people engage with this topic at different conceptual levels.

\section{Pay inequality concerns are not directly tied to pay transparency}

The topic of pay inequality frequently emerged in the interviews and responses could be broadly grouped into two categories: concerns about pay inequality and responses to different or unequal pay. The concerns about pay inequality predominantly focused on perceptions or examples of pay inequality within the participants' organisations, although some more general concerns about pay inequality were also expressed:

'Just being a manager and employing people, I can tell you I've employed four different people doing exactly the same job, in four different salaries.' (P6, male, 44, middle management)

'Meantime, I mean, they're forgetting that obviously I'm going to have access to that information, right. Get there, the guy that was there was earning, like, 19, 20 grand. And at that time, I get there, same position, doing a better job than the guy that was there, I'm kept at 15. Why?' (P13, male, 26, junior management)

'It is really, it is criminal what we see out there, especially in the private sector. It's sad, sad, sad... You find that white people are paid more than black people, but they are doing the same work... You know, it's wrong...I cannot come to work, we are all working, making life, earning a livelihood and find that you are 
getting more and I am getting less. Or I am getting more. It's not right. It's totally wrong.' (P16, male, 35, middle management)

Despite the often strongly expressed views about pay inequality, there was a consistent theme that pay differentiation, or people being paid differently for the same job, could be acceptable if valid reasons for the differentiation were provided:

'Because I know how much effort I put in, but if I'm not the highest then, so be it. There's some reason why the other person got more. They may have come in at a different stage. They may have credentials which I don't.' (P1, male, 45 , senior management)

'If we join at different times, the one who joined earlier of course would always be a notch or several notches up, compared with the other person. So, it doesn't mean that there is any disparity.' (P20, male, 49, senior management)

'I will always acknowledge when someone has worked hard for it. ...but, when people who are very average performers just blindly get paid such big salaries - that annoys me.' (P17, female, 41, middle management)

This group of codes was highlighted as a key theme because despite the discussion on pay inequality, the participants did not make an explicit link to seeing pay transparency as a tool to address it. This is in contrast with the literature (Rosenfeld \& Denice, 2015; Trotter et al., 2017), which positions reducing inequality as one of the key benefits of increased pay transparency. It was unclear whether the participants were just unaware of this school of thought or whether their low expectation of pay transparency from their employers was a contributing factor.

\section{People can conceptualise the benefits and risks of more pay transparency}

Despite the sometimes poor understanding of pay transparency and relatively low value placed on it as discussed in the previous themes, when asked to consider the possible benefits and risks of greater pay transparency, participants provided rich and thoughtful insights. Direct experience of a particular pay transparency approach does not appear to be necessary to have an opinion on its potential impact.

On the benefits side, pay transparency was seen as a motivator for performance by showing employees what they needed to do to earn more or move to the next level:

'You can incentivise people more when they know what they can potentially be working towards. If they understand that I, in this role, am getting paid on par with a male in a similar role, it's fantastic for morale.' (P17, female, 41, middle management)

'But then the upside [of pay transparency] is most probably somebody will say for you to get there, you've got to perform, you've got to do this. Then it's more productivity for the company. At the end of the day, they gain.' (P13, male, 26, junior management)

It was also seen as a mechanism to force employers to behave more fairly regarding pay and reduce discrimination. More information was seen as a way to build trust in the organisation and that it makes fair decisions:

'And I think it's fair for organisations to be transparent, so that there is a principle of equal pay for equal job.' (P16, male, 35, middle management)

'The government's transparency in terms of remuneration, it helps you to make informed decisions. You don't get in there blindly.' (P20, male, 49, senior management)

'The staff then talk, we start questioning, we start getting little bits here and little bits there and maybe we actually form an incorrect picture. It's not $100 \%$ what is happening. We might exaggerate more than it actually is.' ( $\mathrm{P} 4$, female, 56 , semi-skilled)

Two additional benefits of pay transparency emerged, which were not found in the literature. Firstly, pay transparency created a sense of agency (expressed as having a 'voice' in the organisation and feeling some sense of control) and worth. Participants spoke of the satisfaction of knowing what their work is worth and feeling that more information would give them greater agency and 'voice' in the organisation:

'That the whole scenario would be a benefit to everybody. Because, I mean, at the end of day, you want to know what your work is worth to the company.' (P15, female, 38, junior management)

'The benefit would be I would have more say in the company. Our voice is not being heard. I would feel involved in the company.' (P10, female, 30, semi-skilled)

Secondly, that transparency is inherently good and it does not need to be tied to more tangible outcomes:

'I think the transparency did not make it problematic. It actually strengthened the democracy, if I can put it that way, for people to be treated equally. And it's fair that way.' (P16, male, 35, middle management)

'I don't think transparency brings downsides because people, I think, feel comfortable with what they know. So, if they know certain things, I think they almost feel more comfortable.' (P18, female, 52, middle management)

On the risk side, participants were quick to identify the risks of employees being demotivated and disengaged by pay transparency. This is an interesting contradiction to the benefit of increased motivation:

'Yeah, I don't think it's worth it. I know if you had to tell me what my peers earned and I wasn't on the right end of that, I would lose a lot of motivation. So I don't think it would be good.' (P1, male, 45 , senior management)

They also voiced concerns about people not understanding the information and ensuing resentment, lowered morale and animosity between employees. Concerns about the loss of privacy were also expressed:

'I think that being too open about it can be dangerous...I mean, there could be valid criteria for having differences in pay, and if you put it all out there, you know, I think it can lead to a lot of resentment and what have you.' (P8, female, 58, middle management) 
'I believe, you know, what you earn should be your private matter. It shouldn't be common knowledge.' (P6, male, 44, middle management)

Although all these three risks have potential downsides for the employer - demotivated, resentful employees who feel their privacy has been compromised - they are also downsides for the employee.

The other three risks highlighted are more from the employer's side, with some potential benefit for employees. Firstly, one of the most common arguments against pay transparency, inflating costs in the process of redressing inequalities, was raised:

'So I think one of the downsides of that, although it shouldn't be a downside, to being transparent, is that if you are to be truly transparent and therefore, redressing where you need to, it can be quite costly.' (P9, female, 34, middle management)

'And that's where I say transparency is going to cause a problem. Because the company can't afford to just say OK, everyone, you came in here a long time ago and are now underpaid because of that. We're going to just up your salary by $20 \%$. So, that's a challenge.' (P1, male, 45, senior management)

Furthermore, potential reputational damage to the organisation and loss of its competitive advantage were seen as risks:

'I imagine something like this would blow up really quickly. You just need a race or gender card to this and it's viral. It's all over social media and that does more reputational damage.' (P17, female, 41 , middle management)

More subtly, more transparency was seen as a way to shift the information asymmetry that exists between employers and employees more in favour of employees.

Although there were two participants who saw either no benefits or no risks in greater pay transparency, together the group of participants created a rich perspective on the potential benefits and risks of pay transparency.

\section{Discussion}

The objectives of this study were to explore how employees perceive pay transparency and how their experiences with their employers shape their response to different pay transparency practices.

\section{Outline of the results}

The interview data were useful in shedding light on how employees understand pay transparency. The diverse views on pay transparency spanned the continuum of being completely for it to completely against it with tentative support for some limited pay transparency in the middle. Some participants just settled on acknowledging that it is a complex topic. Responses were also influenced by participants' personal experiences whether they had been exposed to pay information in the course of their jobs or whether they had positive or negative pay- related experiences, amongst other things. The compensation activation theory proposes that individuals respond differently to aspects of pay practices depending on how those practices trigger something that is particularly relevant to that individual (Fulmer \& Shaw, 2018). The diversity of views, even within the same organisation, to some extent supports this theory. The findings also complement previous work that found different responses to pay transparency along demographic and personal characteristic lines (Bamberger \& Belogolovsky, 2017; Scott et al., 2015; Smit \& Montag-Smit, 2018).

In addition to their diverse responses, participants clearly had diverse understandings of what pay transparency actually is. The interview data showed that some employees think of it as purely related to the information they receive about their own pay and benefits, whilst some have a sophisticated understanding of the concept. The differences in understanding probably not only contributed to the diversity of responses but also highlighted that interpretations of pay transparency's impact on organisational outcomes should possibly be viewed with some caution. If employees within the same organisation can express very different understandings of the topic, it does cast doubt on how much these practices can be said to be directly influencing organisational outcomes.

Furthermore, the data showed that employees did not have very high expectations of pay transparency from their employer. Many participants appeared to be satisfied that the information they received about pay was normal and what they expected. Even when they had experienced more transparent practices at other employers, this did not appear to translate into an expectation of the same level of transparency as their current employer. Unmet expectations were mainly related to poor communication and opaque processes for salary increases as opposed to wider pay transparency practices.

The diverse views and low expectations of pay transparency made it all the more surprising that participants could articulate a rich and comprehensive list of the potential benefits and risks of greater pay transparency. All the theoretical and empirical perspectives from the literature were expressed in some way in the interviews. Over and above confirming the expected benefits and risks of pay transparency from the literature, two other potential benefits were highlighted, namely that pay transparency can create a sense of agency and worth and that transparency is inherently good and moral. Because these benefits are intangible, it could perhaps explain why they have not been articulated by prior researchers. As these concepts were repeated a number of times by different participants, they are worth highlighting.

\section{The sports fan on the side-lines}

Considering how these quite disparate themes - diverse views and low expectations but comprehensive understanding of benefits and risks - can co-exist and be coherently explained, the metaphor of the sports fan seems most apt. Sports fans can watch from the side-lines and 
comment on their team's performance and the referee's decisions, with a sort of harmonious passion (Bester, Coetzee, \& Van Lill, 2020). Sports fans may have a very sophisticated understanding of the rules and strategies of the game, but they are not on the field actually playing. There is a level of disconnect from the action. Employees may have countless opinions about pay in theory, but in this study they showed a level of disconnect from pay transparency in practice, through their low expectations and their view that it has a weak impact on organisational outcomes. An appreciation for this level of disconnect could be fruitful when considering the impact of pay transparency in an organisation.

\section{Practical implications}

Understanding how employees perceive and respond to pay transparency can help employers to navigate their approach to it. This study shows that employee expectations are often low and employees will probably respond in a diverse set of ways regardless of the approach chosen. This implies that organisations (HR and managers) should focus on what they want to achieve with their chosen approach, rather than on potential employee responses.

\section{Limitations and recommendations}

The sample of 20 interviews across four organisations may limit the transferability of the findings. However, the organisations represent a diverse cross-section of employers, which mitigates the limitation to some extent.

A further limitation is that the sample is skewed towards employees in middle and junior management $(70 \%$ of the total). This may mean that perspectives from higher and lower levels were not adequately represented.

This study focused only on perceptions of pay transparency regarding salaries or base pay. Future research could consider if the findings still hold if other aspects of remuneration are included, for example, bonuses, commission, share incentives or total reward.

\section{Conclusion}

This study contributes to understanding employees' responses to pay transparency, adding a much-needed employee perspective that is currently missing from most of the research on pay transparency. Showing that employees are somewhat disconnected from the 'action' of pay transparency, much like a sports fan on the side-lines, gives practical direction to $\mathrm{HR}$ and remuneration practitioners navigating pay transparency.

\section{Acknowledgements \\ Competing interests}

The authors declare that they have no financial or personal relationships that may have inappropriately influenced them in writing this article.

\section{Authors' contributions}

This article was drawn from the R.S.'s PhD thesis, and as such, she took the lead in the research and the writing of the manuscript. C.M.M. and M.H.R.B. were co-supervisors and provided conceptual input and guidance in the structuring and writing of the manuscript.

\section{Funding information}

This research work received no specific grant from any funding agency in the public, commercial or not-for-profit sectors.

\section{Data availability}

The data that support the findings of this study are available on request from the first author, R.S. The data are not publicly available because of their content that could compromise the privacy of research participants.

\section{Disclaimer}

The views and opinions expressed in this article are those of the authors and do not necessarily reflect the official policy or position of any affiliated agency of the authors.

\section{References}

Almeida, L. (2016). The effects of CEO pay transparency in France: Benchmarking 'catching-up', and outsider scrutiny. Retrieved from https://ssrn.com/ abstract $=2787562$

Alterman, V., Bamberger, P., Wang, M., Koopmann, J., Belogolovsky, E., \& Shi, J. (2020) Best not to know: Pay secrecy, employee voluntary turnover, and the conditioning effect of distributive justice. Academy of Management Journal, In press. https://doi.org/10.5465/amj.2019.0231

Arnold, A., Fulmer, I.S., Sender, A., Allen, D.G., \& Staffelbach, B. (2018). Compensation and pay transparency practices in Switzerland - Survey report 2018. Retrieved from https://doi.org/10.13140/RG.2.2.22956.16005

Baker, S.E., \& Edwards, R. (2012). How many qualitative interviews is enough? Retrieved from http://eprints.ncrm.ac.uk/2273/

Bamberger, P., \& Belogolovsky, E. (2010). The impact of pay secrecy on individual task performance. Personnel Psychology, 63(4), 965-996. https://doi. org/10.1111/j.1744-6570.2010.01194.x

Bamberger, P., \& Belogolovsky, E. (2017). The dark side of transparency: How and when pay administration practices affect employee helping. Journal of Applied Psychology, 102(4), 658-671. https://doi.org/10.1037/apl0000184

Bellé, N. (2015). Performance-related pay and the crowding out of motivation in the public sector: A randomized field experiment. Public Administration Review, 75(2), 230-241. https://doi.org/10.1111/puar.12313

Belogolovsky, E., \& Bamberger, P. (2014). Signaling in secret: Pay for performance and the incentive and sorting effects of pay secrecy. Academy of Management Journal, 57(6), 1706-1733. https://doi.org/10.5465/amj.2012.0937

Bester, M.S., Coetzee, M., \& Van Lill, X. (2020). Exploring the factor structure of the Passion Scale: Are the dualistic types of passion relevant for workers in the South African context? SA Journal of Industrial Psychology, 46, 1-10. https://doi. org/10.4102/sajip.v46i0.1788

Bosch, A., \& Barit, S. (2020). Gender pay transparency mechanisms: Future directions for South Africa. South African Journal of Science, 116(3/4), 1-6. https://doi. org/10.17159/sajs.2020/6772

Birkinshaw, J., \& Cable, D. (2017). The dark side of transparency. McKinsey Quarterly, 2017(1), 1-6.

Braun, V., \& Clarke, V. (2006). Using thematic analysis in psychology. Qualitative Research in Psychology, 3(2), 77-101. https://doi.org/10.1191/14780887 06qp063oa

Bryman, A. (2008). Social research methods (3rd ed.). Oxford: Oxford University Press.

Burroughs, J.D. (1982). Pay secrecy and performance: The psychological research. Compensation Review, 14(3), 44-54. https://doi.org/10.1038/2091178c0

Card, D., Mas, A., Moretti, E., \& Saez, E. (2012). Inequality at work: The effect of peer salaries on job satisfaction. American Economic Review, 102(6), 2981-3003. https://doi.org/10.1257/aer.102.6.2981 
Castilla, E.J. (2015). Accounting for the gap: A firm study manipulating organizational accountability and transparency in pay decisions. Organization Science, 26(2), 311-333. https://doi.org/10.1287/orsc.2014.0950

Colella, A., Paetzold, R.L., Zardkoohi, A., \& Wesson, M.J. (2007). Exposing pay secrecy Academy of Management Review, 32(1), 55-71. https://doi.org/10.5465/ AMR.2007.23463701

Colquitt, J.A. (2001). On the dimensionality of organizational justice: A construct validation of a measure. Journal of Applied Psychology, 86(3), 386-400. https://doi.org/10.1037//0021-9010.86.3.386

Colquitt, J.A., Conlon, D.E., Wesson, M.J., Porter, C.O.L.H., \& Ng, K.Y. (2001). Justice at the millenium: A meta-analytic review of 25 years of organizational justice research. Journal of Applied Psychology, 86(3), 425-445. https://doi. org/10.1037//0021-9010.86.3.425

Creswell, J.W. (2013). Qualitative inquiry and research design: Choosing among five approaches (3rd ed.). Thousand Oaks, CA: Sage.

Creswell, J.W., \& Plano Clark, V.L. (2018). Designing and conducting mixed methods research (3rd ed.). London: Sage.

Cullen, Z.B., \& Pakzad-Hurson, B. (2017). Equilibrium effects of pay transparency in bargaining environments. Retrieved from http://web.stanford.edu/?bph1/ BPHJMP.pdf

Cullen, Z. B. and R. Perez-Truglia. 2018. "The Motivating (and Demotivating) Effects of Learning Others' Salaries." Harvard Business Review. Oct 25, 2018.

Daniel, J. (2012). Sampling essentials: Practical guidelines for making sampling choices. Thousand Oaks, CA: Sage.

Day, N.E. (2011). Perceived pay communication, justice and pay satisfaction. Employee Relations, 33(5), 476-497. https://doi.org/10.1108/01425451111153862

De Coning, J.A., Rothmann, S., \& Stander, M.W. (2019). Do wage and wage satisfaction compensate for the effects of a dissatisfying job on life satisfaction? SA Journal of Industrial Psychology, 45, 1-11. https://doi.org/10.4102/sajip.v45i0.1552

Estlund, C. (2012). Extending the case for workplace transparency to information about pay. UC Irvine Law Review, 4, 781-800.

Frey, B.S., Schaffner, M., Schmidt, S.L., \& Torgler, B. (2013). Do employees care about their relative income position? Behavioral evidence focusing on performance in professional team sport. Social Science Quarterly, 94(4), 912-932. https://doi. org/10.1111/ssqu.12024

Fulmer, I.S., \& Shaw, J.D. (2018). Person-based differences in pay reactions: A compensation-activation theory and integrative conceptual review. Journal of Applied Psychology, 103(9), 939-958. https://doi.org/10.1037/apl0000310

Futrell, C.M., \& Jenkins, O.C. (1978). Pay secrecy versus pay disclosure for salesmen: A longitudinal study. Journal of Marketing Research, 15(2), 214-219. https://doi. org/10.1177/002224377801500204

Hill, A.D., Aime, F., \& Ridge, J.W. (2017). 10 years of data on baseball teams shows when pay transparency backfires. Harvard Business Review Digital Articles. when pay transparency $/ / \mathrm{hbkfires}$. Harvard Business Review Digital Articles. Retrieved from https://hbr.org/2017/05/
shows-when-pay-transparency-backfires

King, N., \& Brooks, J. (2018). Thematic analysis in organisational research. In C. Cassell, A.L. Cunliffe, \& G. Grandy (Eds.), The Sage Handbook of Qualitative Business and Management Research Methods (pp. 219-236). London: SAGE Publications, Ltd.

Kim, M. (2015). Pay secrecy and the gender wage gap in the United States. Industrial Relations, 54(4), 648-667. https://doi.org/10.1111/irel.12109

Lawler, E.E. (1965). Managers' perceptions of their subordinates' pay and of their superiors' pay. Personnel Psychology, 18(4), 413-423. https://doi. org/10.1111/j.1744-6570.1965.tb00296.x

Lawler, E.E. (1966). The mythology of management compensation. Californic Management Review, 9, 11-22. https://doi.org/10.1037/014666

Leventhal, G.S., Michaels, J.W., \& Sanford, C. (1972). Inequity and interpersonal conflict: Reward allocation and secrecy about reward as methods of preventing conflict. Journal of Personality and Social Psychology, 23(1), 88-102. https://doi. org/10.1037/h0032877

Loudenback, T. (2017). More tech companies have stopped keeping employee salaries secret - And they're seeing results. Business Insider. Retrieved from http://www.businessinsider.com/why-companies-have-open-salaries-and-paytransparency-2017-4
Marasi, S., \& Bennett, R.J. (2016). Pay communication: Where do we go from here? Human Resource Management Review, 26(1), 50-58. https://doi.org/10.1016/j. hrmr.2015.07.002

Marasi, S., Wall, A., \& Bennett, R.J. (2018). Pay openness movement: Is it merited? Does it influence more desirable employee outcomes than pay secrecy? Organization Management Journal, 15(2), 58-77. https://doi.org/10.1080/15416 518.2018.1471978

Mas, A. (2014). Does transparency lead to pay compression? National Bureau of Economic Research. Retrieved from https://doi.org/10.3386/w20558

Moriarty, J. (2018). Against pay secrecy. Journal of Applied Philosophy, 35(4), 689-704. https://doi.org/10.1111/japp.12273

Nosenzo, D. (2013). Pay secrecy and effort provision. Economic Inquiry, 51(3), 1779-1794. https://doi.org/10.1111/j.1465-7295.2012.00484.x

Obloj, T., \& Zenger, T. (2020). The influence of pay transparency on inequity, inequality and the performance-basis of pay. HEC Paris Research Paper No. SPE-2020-1359. Retrieved from https://doi.org/http://dx.doi.org/10.2139/ssrn.3523828

Olivier, B.H. (2017). The use of mixed-methods research to diagnose the organisational performance of a local government. SA Journal of Industrial Psychology, 43(1), 1-14. https://doi.org/10.4102/sajip.v43i0.1453

Ramachandran, G. (2012). Pay transparency. Penn State Law Review, 116(4), 1043-1080. https://doi.org/10.3366/ajicl.2011.0005

Rosenfeld, J. (2017). Don't ask or tell: Pay secrecy policies in U.S. workplaces. Socia Science Research, 65, 1-16. https://doi.org/10.1016/j.ssresearch.2017.01.009

Rosenfeld, J., \& Denice, P. (2015). The power of transparency: Evidence from a British workplace survey. American Sociological Review, 80(5), 1045-1068. https://doi. org/10.1177/0003122415597019

Rubery, J., \& Grimshaw, D. (2015). The 40-year pursuit of equal pay: A case of constantly moving goalposts. Cambridge Journal of Economics, 39(2), 319-343. https://doi.org/10.1093/cje/beu053

Scheller, E.M., \& Harrison, W. (2018). Ignorance is bliss, or is it? The effects of pay transparency, informational justice and distributive justice on pay satisfaction and affective commitment. Compensation \& Benefits Review, 50(2), 65-81. https:// doi.org/10.1177/0886368719833215

Scott, D., Antoni, C., Grodzicki, J., Morales, E., \& Peláez, J. (2020). Global pay transparency: An employee perspective. Compensation \& Benefits Review, 52(3), 85-97. https://doi.org/10.1177/0886368720905693

Scott, D., Brown, M., Shields, J., Long, R.J., Antoni, C.H., Beck-Krala, E.J., ... Perkins, S.J. (2015). A global study of pay preferences and employee characteristics. Compensation \& Benefits Review, 47(2), 60-70. https://doi.org/10.1177/0886368715598197

Sieweke, J., Köllner, B., \& Süß, S. (2017). The relationship between employees' objective internal and external pay standing and their job performance: A withinperson analysis. Journal of Business and Psychology, 32(5), 533-546. https://doi. org/10.1007/s10869-016-9457-6

SimanTov-Nachlieli, I., \& Bamberger, P. (2020). Pay communication, justice, and affect: The asymmetric effects of process and outcome pay transparency on counterproductive workplace behavior. Journal of Applied Psychology, 106(2) 230-249. https://doi.org/10.1037/apl0000502

Smit, B., \& Montag-Smit, T. (2018). The role of pay secrecy policies and employee secrecy preferences in shaping job attitudes. Human Resource Management Journal, 28, 304-324. https://doi.org/10.1111/1748-8583.12180

Smit, B., \& Montag-Smit, T. (2019). The pay transparency dilemma: Development and validation of the pay information exchange preferences scale. Journal of Applied Psychology, 104(4), 537-558. https://doi.org/10.1037/apl0000355

Trevor, C.O., \& Wazeter, D.L. (2006). A contingent view of reactions to objective pay conditions: Interdependence among pay structure characteristics and pay relative
to internal and external referents. Journal of Applied Psychology, 91(6), to internal and external referents. Journal of Applied

Trotter, R.G., Zacur, S.R., \& Stickney, L.T. (2017). The new age of pay transparency. Business Horizons, 60(4), 529-539. https://doi.org/10.1016/j.bushor.2017.03.011

Williams, M.L., Brower, H.H., Ford, L.R., Williams, L.J., \& Carraher, S.M. (2008) A comprehensive model and measure of compensation satisfaction. Journal of Occupational and Organizational Psychology, 81(4), 639-668. https://doi. org/10.1348/096317907X248851

Zenger, T. (2016). The case against pay transparency. Harvard Business Review Digital Articles. Retrieved from https://hbr.org/2016/09/the-case-against-pay-transparency 